\title{
Implementation Lessons from a Multifaceted National Newborn Program in Solomon Islands: A Mixed-Methods Study
}

\author{
Shidan Tosif, ${ }^{1 \star}$ Anna Jatobatu, ${ }^{2}$ Anita Maepioh, ${ }^{3}$ Amy Gray, ${ }^{1}$ Katherine Gilbert, ${ }^{4}$ Jan Hodgson,,${ }^{5}$ and Trevor Duke ${ }^{1}$ \\ ${ }^{1}$ Centre for International Child Health, Murdoch Children's Research Institute, Royal Children's Hospital Melbourne, University of Melbourne, \\ Parkville VIC, Australia; ${ }^{2}$ Reproductive and Child Health Department, Ministry of Health and Medical Services, Honiara, Solomon Islands; \\ ${ }^{3}$ Department of Obstetrics and Gynaecology, National Referral Hospital, Honiara, Solomon Islands; ${ }^{4}$ Nossal Institute for Global Health, \\ School of Population and Global Health, University of Melbourne, Parkville VIC, Australia; ${ }^{5}$ Department of Paediatrics, University of Melbourne,
} Parkville VIC, Australia

\begin{abstract}
Multifaceted interventions are important in improving neonatal quality of care and health outcomes. This study describes the implementation of an intervention to improve the quality of newborn care in Solomon Islands, a small island developing state and lower middle-income country in the Western Pacific. Inputs included training, equipment provision, and healthcare system organizational changes. For evaluation, we used a mixed-methods design, using quantitative (audits of health facility equipment, structure, and organization) and qualitative (semi-structured interviews and focused group discussions with healthcare workers) methods. Participants highlighted the practical, interactive, coaching style of training and its short duration as positive features in establishing skills. Training had indirect impacts through improving culture of the workplace, and the evaluation provided a valuable opportunity for reflection of the implementation process for healthcare workers. Facility limitations from equipment deficits and poor condition of clinical areas had implications by limiting the provision of quality care, as well as contributing to healthcare workers feeling undervalued. Resuscitation of a nonbreathing baby was a stressful experience for many health workers, compounded by geographic isolation and feeling unsupported. Our findings highlight the importance of training methodology, impact from structural limitations, and experience of resuscitation for the healthcare worker. Attention to these factors may help the design and implementation of newborn care programs in similar contexts.
\end{abstract}

\section{INTRODUCTION}

Implementation strategies that target multiple areas of the health system are needed for improvements in clinical care in low-income countries. ${ }^{1}$ The development, implementation, and monitoring of national packages to improve neonatal quality of care have been a longstanding priority in global health to improve morbidity and mortality. ${ }^{2,3}$ While describing the outcomes of multifaceted interventions, there is a need to explain the impact of these interventions within the health system context to understand the factors that support or inhibit quality care. ${ }^{4,5}$

Previous studies exploring implementation of programs for maternal and newborn care have highlighted broad, important contextual factors such as impact from structural and cultural barriers in Namibia, ${ }^{6}$ family preferences and service availability in Laos, ${ }^{7}$ performance incentives in Malawi, ${ }^{8}$ and the impact of opinion leaders and funding in three countries in Asia. ${ }^{9}$ Fewer descriptions of implementation strategies are available from low- and middle-income countries than from high-income countries, ${ }^{1}$ and we found no reports of implementation strategies describing the experience in the unique context of small island developing states. ${ }^{10}$

Solomon Islands is a lower-middle income country and small island developing state in the Western Pacific. Calculated estimates suggest neonatal mortality rates were 13 per 1,000 live births in 2013. ${ }^{11}$ However, these estimates are incongruous with reports of high perinatal mortality rates $^{12-16}$ and the higher rates of mortality seen in neighboring countries in the Western Pacific that have similar health and demographic profiles. ${ }^{15,17}$ The country is attempting to

*Address correspondence to Shidan Tosif, Centre for International Child Health, University of Melbourne, 50 Flemington Rd., Parkville VIC 3052, Australia. E-mail: shidan.tosif@rch.org.au improve neonatal quality of care through a national rollout of a package of tailored interventions through the framework of the Action Plan for Healthy Newborns in the Western Pacific. ${ }^{18,19}$ The package consists of the implementation of healthcare worker training in newborn care with the World Health Organization's Early Essential Newborn Care EENC program, provision of equipment according to minimum standards for newborn health, and health system organizational changes.

Similar to other lower middle-income countries, in Solomon Islands, most neonatal deaths occur because of complications of preterm birth, intrapartum-related complications, and sepsis. $^{20,21}$ Essential newborn care and basic neonatal resuscitation are interventions that have the most impact on reducing preventable neonatal deaths and stillbirths. ${ }^{22}$ Essential newborn care practices include clean birth processes, thermal considerations through skin-to-skin contact and ambient temperature control, support and initiation of exclusive breastfeeding, and hygienic cord care, as well as reduction of potentially harmful practices such as early bathing and unnecessary suctioning. ${ }^{23-25}$ Previous assessments have recommended strategies to improve neonatal quality of care during and immediately after birth to include these measures. ${ }^{18}$

Description of the intervention. The Ministry of Health, through a collaboration with Solomon Island pediatricians, WHO, and United Nations International Children's Emergency Fund (UNICEF), developed and implemented a multifaceted intervention to improve the quality of newborn care using three approaches: 1) coaching in WHO EENC, 2) supply of basic equipment, and 3) healthcare service delivery changes (see Table 1 for intervention details). For this evaluation, the conceptual framework by Austin et al. ${ }^{26}$ was used, which builds on the Donebedian framework, ${ }^{27}$ for its specific relevance to understanding the drivers behind facility-based quality care. 
Quality of care components were mapped to the framework for the intervention (see Figure 1). The framework was useful for considering the three levels of health system (community, province, and national facilities), of specific relevance to the physically isolated and disparate health facilities in Solomon Islands, with a historically high facility-based birth rate. ${ }^{18}$

The intervention was preceded by a baseline analysis, ${ }^{21}$ followed by a regional implementation plan, ${ }^{18}$ and incorporated EENC implementation guidelines. ${ }^{24}$ The intervention was adapted to local needs using a participatory planning process, through regular meetings with key stakeholders and site visits.

This present mixed-method study was embedded within the intervention with the aim of describing the barriers and facilitators of the implementation of a multifaceted intervention for newborn care and identifying avenues for future successful scale-up.

\section{METHODS}

Study design. Data were collected between 2014 and 2017 using quantitative and qualitative methods (see Supplemental Appendix 1). Quantitative sources included facility equipment and supply audits. Qualitative sources included semi-structured interviews (SSIs) and focus group discussions (FGDs) with front-line healthcare providers, and is described using the consolidated criteria for reporting qualitative research. ${ }^{28}$

Setting and context. Solomon Islands is a lower middleincome country with an estimated population of 599,419
(2016) across six major islands and more than 900 smaller islands. ${ }^{29}$ The country is recovering from a period of civil conflict between 1998 and 2003, during which there was widespread disruption to health services, infrastructure, and economy. ${ }^{30}$ Over the past 10 years, the country has suffered casualties and damage from floods (2014), and earthquake and tsunami $(2007,2013$, and 2016). The national population is young and entering the reproductive age, with $41 \%$ younger than 15 years. $^{31}$

This study took place at the National Referral Hospital $(\mathrm{NRH})$ and the four largest provincial hospitals (Gizo Hospital, Kil'ufi Hospital, Makira Hospital, and Good Samaritan Hospital). The chosen study sites provided a purposive sample based on accessibility and representation of the most populated provinces in the country (see a previous study for descriptions ${ }^{21}$ ).

Quantitative methods. We used a standardized assessment tool for quality of hospital care by the WHO modified for Solomon Islands ${ }^{32}$ and used in neighboring Papua New Guinea, ${ }^{33}$ which aligned with the WHO essential device list for reproductive, maternal, newborn and child health, ${ }^{34}$ and the WHO Pocket Book of Hospital Care for Children. ${ }^{35}$ Using this tool, provincial hospitals were audited for 44 items in the domains of equipment and supplies, ward organization, infection control, and staff providing neonatal care. Data from the audit were compiled into a summary descriptive table of 14 essential structural items at evaluation.

Qualitative methods. The qualitative design used an inductive approach, with iterative analysis conducted simultaneous

TABLE 1

Description of intervention according to effective practice and organization of care taxonomy ${ }^{57}$

\begin{tabular}{|c|c|c|}
\hline Barrier identified & Feature of intervention & Description \\
\hline $\begin{array}{l}\text { Organizational and workplace culture } \\
\text { barriers }\end{array}$ & $\begin{array}{l}\text { Healthcare system culture and } \\
\text { organizational engagement, change, } \\
\text { and support }\end{array}$ & $\begin{array}{l}\text { We facilitated stakeholder involvement in } \\
\text { policy decisions and a local consensus } \\
\text { process through a Newborn Steering } \\
\text { Committee. We involved local opinion } \\
\text { leaders within the } \\
\text { Ministry of Health, pediatric, and } \\
\text { obstetric departments. We } \\
\text { consolidated efforts across } \\
\text { stakeholder agencies to avoid } \\
\text { programmatic duplication. A focal } \\
\text { person for newborn care was appointed } \\
\text { as the main coordinator and resource } \\
\text { person for neonatal training and } \\
\text { support. }\end{array}$ \\
\hline $\begin{array}{l}\text { Structural issues: Basic equipment, } \\
\text { organization, and maintenance }\end{array}$ & $\begin{array}{l}\text { Equipment provision, training, and } \\
\text { technical support }\end{array}$ & $\begin{array}{l}\text { We supplied additional equipment to } \\
\text { reach minimum standards and } \\
\text { provided training on use and basic } \\
\text { technical aspects (see Supplemental } \\
\text { Appendix 1). SCN layout was altered to } \\
\text { position resuscitation equipment close } \\
\text { to delivery areas. We ensured } \\
\text { equipment was entered onto the } \\
\text { national registry for medical assets and } \\
\text { technical support. }\end{array}$ \\
\hline $\begin{array}{l}\text { Healthcare worker knowledge and skill } \\
\text { gaps }\end{array}$ & $\begin{array}{l}\text { Newborn care training and supportive } \\
\text { supervision }\end{array}$ & $\begin{array}{l}\text { We implemented a training program and } \\
\text { distribution of educational materials } \\
\text { (EENC pocketbook) through } \\
\text { educational outreach visits to each } \\
\text { province. Small group EENC coaching } \\
\text { sessions occurred at all provincial } \\
\text { hospitals with healthcare workers from } \\
\text { each province. }\end{array}$ \\
\hline
\end{tabular}




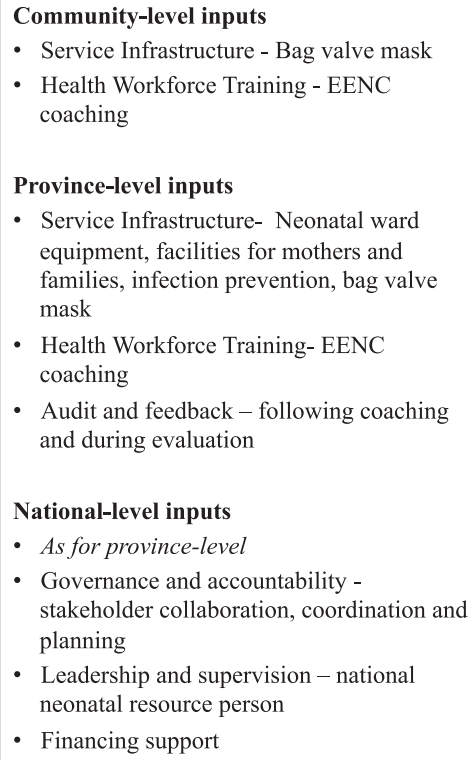

FIGURE 1. Conceptual framework for intervention adapted from Austin et al. ${ }^{26}$

to data collection enabling the main themes to be refined with subsequent data collection. ${ }^{12,36}$

The interview guide and FGD questions were developed to align with domains and constructs of the Theoretical Domains Framework. ${ }^{37}$ Experienced qualitative researchers reviewed the guide (A. G. and J. H.), and it was trialed by the country team (A. J., A. M., and S. T.) and then adjusted to ensure language and terminology were appropriate to the local context. Probe questions were included in the protocol to allow interviewers to follow threads of inquiry as required (see Table 2).

TABLE 2

Interview questionnaire

\begin{tabular}{|c|c|c|}
\hline Domain & Question & Probe \\
\hline Professional role and identity & What role do you have in providing newborn care? & \\
\hline Social norms & $\begin{array}{l}\text { Who else works with you in caring for newborns? } \\
\text { How have you found your working relationship } \\
\text { with others when providing newborn care? }\end{array}$ & What works/does not work? \\
\hline \multirow[t]{3}{*}{ Beliefs about capabilities } & How do you feel when looking after newborn babies? & $\begin{array}{l}\text { Can you describe your confidence, skills, } \\
\text { and knowledge? }\end{array}$ \\
\hline & $\begin{array}{l}\text { What are the challenges you experience when caring } \\
\text { for newborns? }\end{array}$ & Structural/equipment/skills/resources \\
\hline & $\begin{array}{l}\text { What do you think needs to change for better } \\
\text { newborn care? }\end{array}$ & Examples of change \\
\hline Skills, knowledge, and emotion & $\begin{array}{l}\text { In Solomon Islands, some babies are born that do } \\
\text { not breath, or are born "flat." Have you } \\
\text { experienced this? What did you do? }\end{array}$ & $\begin{array}{l}\text { Did you use a bag/mask? } \\
\text { How did you feel during, and after? } \\
\text { Did you feel comfortable using the bag/ } \\
\text { mask? }\end{array}$ \\
\hline \multirow[t]{2}{*}{ Beliefs about consequences } & $\begin{array}{l}\text { How would you prioritize future activities for } \\
\text { newborn care in Solomon Islands? }\end{array}$ & $\begin{array}{l}\text { Training, resources, personnel, and } \\
\text { equipment }\end{array}$ \\
\hline & $\begin{array}{l}\text { What would you like to see changing in newborn care } \\
\text { in the next } 2 \text { years? }\end{array}$ & \\
\hline \multirow[t]{4}{*}{ Environmental context and resources } & What training have you had in newborn care? & $\begin{array}{l}\text { How have you found the EENC coaching } \\
\text { method compared with previous } \\
\text { training methods? }\end{array}$ \\
\hline & $\begin{array}{l}\text { Did you observe any difference between these } \\
\text { trainings? }\end{array}$ & \\
\hline & $\begin{array}{l}\text { What has the greatest impact on your clinical } \\
\text { practice and why? }\end{array}$ & \\
\hline & Has newborn care changed in the last three years? & $\begin{array}{l}\text { How has it changed? What has/has not } \\
\text { helped? }\end{array}$ \\
\hline \multirow[t]{2}{*}{ Goals } & $\begin{array}{l}\text { What has been the biggest challenge to newborn } \\
\text { care? }\end{array}$ & $\begin{array}{l}\text { Training, resources, personnel, and } \\
\text { equipment }\end{array}$ \\
\hline & $\begin{array}{l}\text { What do you think will make the most difference in } \\
\text { improving newborn care? }\end{array}$ & \\
\hline
\end{tabular}


Participants were selected to reflect the varying cadres and roles/responsibilities of healthcare workers in the implementation of the program. Eligible study participants were doctors, nurses, midwives, and nurse-aides who were involved in the provision of neonatal care during the study period and who had attended EENC training.

Two female Solomon Islander midwife researchers (A. J. and A. M.) and one male pediatrician from Australia (S. T.) trained in qualitative methods conducted the interviews and FGDs. Interviews were carried out at the familiar location of the hospital's postnatal or training area and conducted in English and Solomon Islands' Pigin according to the preference of the interviewee(s). There were no observers or nonparticipants during interviews or FGDs.

Interviews were audio-recorded using a portable electronic device, with field notes made during and immediately after interviews. Audio recordings were transcribed verbatim (ST) and translated into English where required.

Data analysis. Interview transcripts were entered into Nvivo software (QSR International Pty Ltd., Melbourne, Australia, version 12, 2018) for storage, coding, and analysis. The first four transcripts were coded by three researchers independently to check for consistency. Further rigorous inductive analysis was undertaken to facilitate development of common themes. Qualitative were then triangulated with quantitative findings, to identify areas of convergence or divergence.

Ethical considerations. Ethics approval for this study was obtained from Solomon Islands Health Research and Ethics Review Board (project number HRE033/16) and the University of Melbourne Human Research Ethics Committee (HREC number 1646267.1). Written informed consent was obtained before interviews and FGDs. This study adheres to the Standards for Reporting Implementation Studies framework. ${ }^{38}$

\section{RESULTS}

Health facility audits. Results of the facility audits at baseline and at the end of the study period are shown in Table 3. Barriers to equipment delivery were logistical difficulties, long delays in delivery, and lack of technical expertise in installation. The number of bag and mask devices did not change substantially during the implementation despite additional units supplied, which were likely passed onto smaller clinics in greater need. However, compared with baseline, all bag and masks were assembled and within reach of the resuscitation area at the end of the study period. Neonatal monitoring devices were available, but not in routine use because of challenges with setup and troubleshooting technical errors. Infection control improvement was mixed, with improvement in two hospitals (Kirakira and Good Samaritan) and problems arising from refill of hand hygiene dispensers. Oxygen concentrator availability increased slightly, with two new concentrators in use at $\mathrm{NRH}$ and one at Kil'ufi Hospital. Multiple pieces of equipment (e.g., oximeters and concentrators) were affected by simple technical problems for which servicing was not available, rendering them unusable. Many hospital buildings remained in poor states of repair, apart from in Gizo, where a new hospital had been completed in 2012 following a tsunami and earthquake.

Qualitative results. A total of 33 participants (31 females and two males) from five hospitals were involved in the study. Recruitment continued until data saturation was evident; when no new themes emerged from data. ${ }^{39}$ This occurred following eight FGDs and five SSIs. There were no healthcare workers who declined participation. The median age was 38 years (IQR 36-43), and the median years of experience was 12 years (IQR 8-20).

TABLE 3

Equipment, organization, and supplies at baseline and final audit

\begin{tabular}{|c|c|c|c|c|c|c|c|c|c|c|}
\hline \multirow[b]{2}{*}{ Assessment } & \multicolumn{2}{|c|}{ Kil'ufi Hospital } & \multicolumn{2}{|c|}{ Kirakira Hospital } & \multicolumn{2}{|c|}{ Gizo Hospital } & \multicolumn{2}{|c|}{$\begin{array}{l}\text { Good Samaritan } \\
\text { Hospital }\end{array}$} & \multicolumn{2}{|c|}{ National referral hospital } \\
\hline & Baseline & Final & Baseline & Final & Baseline & Final & Baseline & Final & Baseline & Final \\
\hline $\begin{array}{l}\text { Self-inflating } \\
\text { resuscitation bags }\end{array}$ & 3 & $2(-)$ & 2 & $3(+)$ & 2 & $1(-)$ & 2 & $3(+)$ & 4 & $3(-)$ \\
\hline $\begin{array}{l}\text { Bag and mask } \\
\text { assembled and } \\
\text { within reach of } \\
\text { resuscitation area }\end{array}$ & No & Yes (+) & No & Yes (+) & No & Yes (+) & No & $\begin{array}{c}\text { Yes } \\
(+)\end{array}$ & No & No \\
\hline Oxygen cylinder & 1 & 1 & 1 & 1 & 0 & 0 & 1 & 1 & 1 & 1 \\
\hline Oxygen concentrator & 0 & $2(+)$ & 0 & 0 & 1 & 1 & 1 & 1 & 2 & $3(+)$ \\
\hline $\begin{array}{l}\text { Oximeter with neonatal } \\
\text { probes }\end{array}$ & 1 & 1 & 1 & $0(-)$ & 1 & 1 & 1 & 0 & 1 & 1 \\
\hline Overhead warmer & 1 & 1 & 0 & $2(+)$ & 2 & 2 & 0 & $1(+)$ & 3 & $6(+)$ \\
\hline Phototherapy system & 1 & $2(+)$ & 1 & 1 & 2 & 2 & 1 & 1 & 3 & 1 \\
\hline $\begin{array}{l}\text { Designated } \\
\text { resuscitation area }\end{array}$ & Yes & Yes & No & Yes (+) & Yes & Yes & No & $\begin{array}{l}\text { Yes } \\
(+)\end{array}$ & Yes & Yes \\
\hline Overcrowding & No & No & Yes & No & No & No & Yes & No (-) & Yes & Yes \\
\hline $\begin{array}{l}\text { Washbasin, soap, and } \\
\text { water }\end{array}$ & No & No & No & Yes & No & Yes & No & No & No & No \\
\hline $\begin{array}{l}\text { Alcohol hand gel } \\
\text { dispenser and filler }\end{array}$ & Yes & Yes & No & Yes & Yes & Yes & No & $\begin{array}{l}\text { Yes } \\
(+)\end{array}$ & No & Yes (+) \\
\hline $\begin{array}{l}\text { State of building repair } \\
\text { and maintenance }\end{array}$ & Satisfactory & Poor (-) & Poor & Poor & Excellent & Excellent & Poor & Poor & Poor & Poor \\
\hline $\begin{array}{l}\text { Continuous electricity } \\
\text { supply }\end{array}$ & No & Yes (+) & $\begin{array}{l}\text { Occasional } \\
\text { interruption }\end{array}$ & $\begin{array}{l}\text { Occasional } \\
\text { interruption }\end{array}$ & Yes & Yes & Yes & Yes & $\begin{array}{l}\text { Occasional } \\
\text { interruption }\end{array}$ & $\begin{array}{l}\text { Occasional } \\
\text { interruption }\end{array}$ \\
\hline $\begin{array}{l}\text { Continuous running } \\
\text { water }\end{array}$ & Yes & Yes & Yes & Yes & Yes & Yes & Yes & Yes & Yes & Yes \\
\hline
\end{tabular}


Three main themes were identified from participant attitudes toward the implementation process and newborn care, including 1) training methods empowered learning and confidence, 2) resuscitation can be a stressful experience, and 3) valuing participation in research and nontraining intervention components.

Training methods empowered learning and confidence. Coaching methods. Coaching methodology was identified as a positive feature of the intervention, and participants associated it with better retention of knowledge and skills in clinical care. Participants described the difference in the coaching methodology and its practical approach as compared with previous training styles experienced. They expressed a sense of fatigue from didactic methods. Participants spoke to the benefits of having the training modules within existing workspaces and felt that it brought an added sense of reality to the simulations.

"the hands-on style is best, [better] than looking at the slide lectures, it's nice that we did the hands-on [training]... So I think that style should be continued with every training." (Midwife, FGD)

Program duration and practical approach. Participants highlighted the short duration of the program and practical approach as compared with past training programs, which were up to 1-week duration and included more theory. The higher degree of repetition and hands-on learning was identified as having greater relevance to daily duties.

"I find it very useful. . . it's a short period of time and a lot of information given, it is very useful, easily remembered as compared to other workshops [where] more theory takes longer."(Neonatal nurse, SSI)

Enhanced communication between cadres. Participants recognized a healthcare cultural change from the program and its impact on communication. The training provided a universal language and expected standard for newborn care. Because of all staff at each facility receiving the training together, there was cross-disciplinary interaction, with participants of all cadres training with the same expectations, a feature not common to previous trainings where midwives and nurses would train separate to doctors.

"it [is] good because we are speaking the same language and everyone [knows] what to do next especially [in] resuscitations everybody knows each other so if they need help they know exactly what should come next. [It] is [a] certain procedure they know, it helps the anaesthetists, surgeons paediatricians obstetricians to work together." "(Neonatal nurse, SSI)

Increased confidence. There was a common expression of increased confidence in the management of the nonbreathing newborn following training. This was reflected in both a practical sense for skills acquisition and competency through knowledge gains. Participants recounted examples of instances where their confidence had enabled autonomy and earlier recognition, and intervention in caring for a nonbreathing newborn.
"I see most of the staff [have] gain[ed] more confidence in resuscitating the newborns. Whenever they prepare the area for the second stage they prepare for the newborns." (Midwife, FGD)

Stressful nature of resuscitation experience. Participants commonly found resuscitation of a nonbreathing neonate to be stressful and challenging. The "high stakes" moment affected adherence to skills and knowledge that participants felt they otherwise would be able to perform. Often these situations were compounded by a sense of isolation, lack of support, and not having anyone to assist. When resuscitation occurred after hours with fewer staff and lack of amenities such as electricity, stress was amplified.

"Even though we are trained... in those situations sometimes we will panic, and then we forget something we must or have to do, but later on we just think about it." (Neonatal nurse, FGD)

Reflection on positive resuscitation experiences. Several participants described a successful resuscitation where they reflected on the application of their skills and making a difference. At times, these moments were associated with surprise that a rare, positive outcome for the baby could be achieved through their actions, reflecting the preexisting lack of expectation of success for intervening with nonbreathing babies. When successful, these high-stake moments imbued a sense of satisfaction and trust in their own skills:

"yes everyone was surprised, and when I told the mother the baby was breathing again she was very happy, because someone said, the other doctors said, "oh your baby is not breathing, you might lose the baby." So I just continued [to] bag... and the baby picked up, so I just learnt from that, when I do that I just help the baby breathe, and I feel happy too because it's a miracle for me." (Midwife, SSI)

Improved autonomy with training. Following training, participants felt increased autonomy during resuscitation, especially in cadres of midwives. Interviewees felt a reduced reliance on doctors and more confident in their own skills.

"I think the EENC really helps us to, to build our skills and feel confident, not like before we used to call the doctors every time there was born a flat baby and we go panic." (Midwife, FGD)

Need for ongoing practice. Participants expressed lack of practice, due to the infrequent nature of resuscitation as a challenge for maintaining skills. Most participants felt that more regular training and refreshers of short duration would be beneficial. In-house training, of regular frequency was frequently cited-to occur monthly or weekly.

"we should do it on our own, like once a week we practice, or fortnightly we do that practice on how to do the resuscitation. That would remind us." (Nurse aide, FGD)

Valuing participation in evaluation. Participants expressed they valued the opportunity to reflect and analyze their experience through the process of the evaluation interviews and group discussions. Participants said that they had not 
received feedback from previous evaluations. There were differing opinions with regard to where responsibility for future evaluation of newborn care should lie. Some participants felt that external evaluation would hold them to greater accountability and would identify gaps, but others felt that there was a need to take ownership of this process.

"can we just say that if you compile everything, then it would be good for us to have our feedback as well? Then we will know where the gaps are. Just last week we had a meeting and we sort of talked it over, about our nurses in our ward, [that] they should have a team where they do their own evaluation on how they do things. But I think its better for us to have an external evaluation team as well so that maybe if we look at ourselves then we think we are all good but maybe there are gaps that we have so its good that you people are coming to do the external evaluation for our program." (Midwife, FGD)

Non-training intervention components. Structural impact on quality of care processes. When asked to prioritize future needs, many interviewees cited equipment and structural improvements over training priorities. Problems with physical conditions such as the state of buildings and conditions were identified. Oxygen supply interruptions and equipment technical issues were highlighted as limitations of the intervention. These structural limitations often had an impact on what healthcare workers knew to be the best practice and frustrated their ability to provide quality care in their patient's interests.

"For me, the training is good, is best, but facilities are the one, the training is already there, but because there is not enough facilities, like rooms/beds, we don't follow 90 minutes [of skin-to-skin contact], as long as mother is delivered and baby is lying there, we just go [to the postnatal ward]. We need more beds."(Midwife, FGD)

Impact of structural elements on healthcare worker attitudes. A sense of personal and professional value was imbued when resources were available. This impacted both practical elements in providing care, as well as imparting a sense of valuing of the healthcare worker's role and purpose:

"Previously when we didn't have the pulse oximeter, the neonate they were already cyanosed because we didn't have a machine to check. But after they delivered it, the staff they feel they're working very well." (Midwife, FGD)

Healthcare organization limitations. Participants cited challenges that were not addressed by the intervention such as few staff, limited support after hours, and feeling unsupported, particularly when senior assistance was required. Contacting doctors by mobile phones and requesting attendance for emergencies were often protracted, with doctors citing delays due to transport and communication issues.

"Sometimes when there is a lot of mothers that come for delivery, then I myself or only one nurse is attending to the newborn, so it's a little bit hard." (Midwife, SSI)

\section{DISCUSSION}

In this mixed-method study of the implementation experience of healthcare workers of a multifaceted intervention to improve neonatal quality of care, participants describe the challenge of newborn resuscitation in remote settings. They describe it as an infrequent, high-stake occurrence compounded by feeling unsupported. Participants expressed the interrelation of facilities (structure) and skills (process) impacting on their ability to provide care, both practically through limited space and poor conditions, as well as through a sense of their physical environment reflecting value of their professional role. The practical coaching methodology without didactic methods, and short-training periods were strengths of the program. Increased recognition of the need to practice skills between formal trainings was expressed although opportunities to do this were limited.

We found the pedagogical approach of training to be an enabling feature in impacting change in practice and attitudes from the intervention. As part of this study, the EENC training used a brief (2-day) scenario-based approach with an interactive coaching supervisor in small groups. Neonatal training programs in low- and middle-income countries vary significantly in content, methods, and duration. Previous studies of a shorter 1-day duration have also shown impact. ${ }^{40}$ The use of coaching methodology, and absence of didactic teaching, differs from previously reported neonatal training programs. ${ }^{41-43}$ Indirect impacts of the coaching method were workforce cultural changes, through improved collaboration and communication between cadres.

Through qualitative data, a sense of anxiety regarding resuscitations and a lack of confidence was identified, with successful resuscitation experiences being a welcome exception rather than the norm. Few studies have documented the qualitative experience of resuscitation for healthcare workers in low- and middle-income countries. ${ }^{44-47}$ Whereas many studies and guidelines outline the equipment, algorithms, and approach, the challenging nature of a resuscitation event, and its subsequent weighing on the mind of the healthcare worker, is not well described. Support in dealing with stressful experiences is an important component of a well-performing and motivated workforce. ${ }^{48}$ Providing geographically isolated healthcare workers avenues for postresuscitation debriefing and reflection is important for wellbeing and provides a training moment.

Interrelation between structure and process components reinforces the implementation framework and the drivers for quality care. The lack of physical resources leads to a sense of frustration for healthcare workers, a barrier to providing basic newborn care. ${ }^{49}$ Structural limitations impeding process improvements such as implementation of skin-to-skin contact because of space limitations have been experienced in other settings. ${ }^{50}$ In countries with small, disbursed populations, health facility infrastructure is costly, and maintenance and technical support are challenging, with many facilities across a large geographical areas.

Several studies have evaluated the impact from the implementation of programs for newborns and children, and have highlighted the impact of context on intervention delivery. ${ }^{7,51-53}$ Multifaceted or "packaged" interventions 
were not found to have a strong evidence base, and were highlighted as a priority area for research on strategies that make scale-up feasible. ${ }^{4}$ Multifaceted studies vary significantly in terms of components, and direct comparisons are difficult. In this study, we found the concomitant training, attention to structural changes, and equipment implementation synergistic. Neonatal training could occur with new equipment, in familiar settings. This concept supports the idea of an "enabling environment" through equipment, supplies, medications, and transportation for referral. ${ }^{54}$ The opportunity to combine various intervention components (e.g., equipment delivery and training) because of infrequent opportunity to travel to remote sites, and the associated time and funds needed, further underscored this approach.

The unique combination of economic, climatic, and geographical challenges facing lower-middle-income small island developing states presents a challenge to the implementation of timely high-impact health interventions, which have been possible in other regions. The Oceania region contains 20 small island developing states and has had few opportunities to evaluate the impact of neonatal interventions within its unique context. Barriers to delivering appropriate supplies and equipment include servicing geographically disbursed populations, high costs for transportation that consume a limited financial budget, ${ }^{55}$ and disruption to services from weather events. Some countries have needed to import health services and support medical travel for access to healthcare services, although this has high associated costs and requires significant coordination and oversight. ${ }^{56}$ Themes arising from both qualitative and quantitative sections of this article reflect the impact of geographic isolation and lack of supports, underscoring the need for relationships between community, provincial, and national hospitals to be supported. ${ }^{26}$ Training methods must support increased autonomy where support and expertise may not be available.

Limitations of this study include sampling methods, which depended on the participation of staff at the study sites on the days of the refresher training. Several healthcare workers were unable to participate because of lack of transport to reach the provincial hospital; hence, only a minority of our participants were from outside these facilities. Therefore, the views represented need to be interpreted with caution, beyond the settings of provincial hospitals. Second, the participants knew some of the researchers from the intervention. Although this may have affected the expression of criticism of the implementation limiting validity of this study, triangulation from across the study sites and healthcare workers yielded consistent themes. This approach occurred out of pragmatic necessity due to access and timing of visits to the provincial hospitals, and limited available individuals with experience of this thematic area and the context of implementation, a challenge experienced by other similar research in low- and middle-income countries. ${ }^{7}$

\section{CONCLUSION}

This implementation experience provided important lessons that could be targeted by future iterations of newborn care programs. Practical, coaching-based training methods enabled improved confidence in healthcare workers and communication between various cadres of the healthcare workers. Challenges include the stressful nature of resuscitation, structural limitation, and few opportunities for ongoing skill practice. These findings may be used to shape future interventions to improve newborn quality of care in similar settings.

Received August 26, 2019. Accepted for publication November 24, 2019.

Published online January 20, 2020.

Note: Supplemental Appendices appear at www.ajtmh.org.

Acknowledgments: This work would not have been possible without the support of the Ministry of Health and Medical Services, and Divinal Ogaoga, the pediatricians, and registrars at the National Referral Hospital: Titus Nasi, Carol Titiulu, Steven Lumasa and Janella Solomon, and Rami Subhi.

Disclosure: A. M., A. J., and S. T. were involved in the implementation activities of the newborn care program in Solomon Islands.

Authors' addresses: Shidan Tosif, Amy Gray, and Trevor Duke, Centre for International Child Health, Murdoch Children's Research Institute, Royal Children's Hospital Melbourne, University of Melbourne, Parkville VIC, Australia, E-mails: shidan.tosif@rch.org.au, amy.gray@rch.org.au, and trevor.duke@rch.org.au. Anna Jatobatu, Reproductive and Child Health Department, Ministry of Health and Medical Services, Honiara, Solomon Islands, E-mail: ajatobatu@moh.gov.sb. Anita Maepioh, Department of Obstetrics and Gynaecology, National Referral Hospital, Honiara, Solomon Islands, E-mail: amaepioh@nrh.gov.sb. Katherine Gilbert, Nossal Institute for Global Health, School of Population and Global Health, University of Melbourne, Parkville VIC, Australia, E-mail: katherine.gilbert@unimelb.edu.au. Jan Hodgson, Department of Paediatrics, University of Melbourne, Parkville VIC, Australia, E-mail: katherine.i.gilbert@gmail.com.

\section{REFERENCES}

1. Pantoja T et al., 2017. Implementation strategies for health systems in low-income countries: an overview of systematic reviews. Cochrane Database Syst Rev 9: CD011086.

2. Martines $J$ et al., 2005. Neonatal survival: a call for action. Lancet 365: 1189-1197.

3. Ridde V, 2016. Need for more and better implementation science in global health. BMJ Global Health 1: e000115.

4. Haws RA, Thomas AL, Bhutta ZA, Darmstadt GL, 2007. Impact of packaged interventions on neonatal health: a review of the evidence. Health Policy Plan 22: 193-215.

5. English M, Nzinga J, Mbindyo P, Ayieko P, Irimu G, Mbaabu L, 2011. Explaining the effects of a multifaceted intervention to improve inpatient care in rural Kenyan hospitals-interpretation based on retrospective examination of data from participant observation, quantitative and qualitative studies. Implement Sci 6: 124

6. Wesson J, Hamunime N, Viadro C, Carlough M, Katjiuanjo P, McQuide P, Kalimugogo P, 2018. Provider and client perspectives on maternity care in Namibia: results from two crosssectional studies. BMC Pregnancy Childbirth 18: 363.

7. Gray AZ, Soukaloun D, Soumphonphakdy B, 2017. A qualitative study of provider perceptions of influences on uptake of pediatric hospital guidelines in Lao PDR. Am J Trop Med Hyg 97: 602-610.

8. Brenner S, Wilhelm D, Lohmann J, Kambala C, Chinkhumba J, Muula AS, De Allegri M, 2017. Implementation research to improve quality of maternal and newborn health care, Malawi. Bull World Health Organ 95: 491-502.

9. Bergh AM, de Graft-Johnson J, Khadka N, Om'Iniabohs A, Udani R, Pratomo H, De Leon-Mendoza S, 2016. The three waves in implementation of facility-based kangaroo mother care: a multi-country case study from Asia. BMC Int Health Hum Rights 16: 4.

10. United Nations, 2011. Office of the High Representative for the Least Developed Countries Landlocked Developing Countries and Small Island Developing States. Small Island Developing States. New York, NY: USA UN-OHRLLS. 
11. United Nations Inter-agency Group for Child Mortality Estimation, 2014. Levels and Trends in Child Mortality Report 2014. New York, NY: United Nations Children's Fund.

12. Strauss AL, 1987. Qualitative Analysis for Social Scientists: Cambridge [Cambridgeshire]. New York, NY: Cambridge University Press.

13. Jones PD, Balasundaram N, D'Costa L, Kacker K, Kaludewa A, Fink J, 2018. High perinatal mortality rates persist in Kirakira: the sustainable development goals for health remain out of reach in the provinces of Solomon Islands. $J$ Paediatr Child Health 54: 895-899.

14. Hill S, Martiniuk A, Jagilly H, Black K, 2018. Quantifying the antenatal care, maternal and perinatal outcomes at the second largest hospital in Solomon Islands (2014-2016). Aust N Z J Obstet Gynaecol 58 (Supp. 1): 56.

15. United Nations Children's Fund, 2017. Level and Trends in Child Mortality Report 2017. New York, NY: United Nations Children's Fund.

16. Solomon Islands National Statistical Office, 2015. Solomon Islands Demographic and Health Survey, Honiara, Solomon Islands: Solomon Islands Ministry of Health and Medical Services and the Pacific Community 2017.

17. Duke $T$ et al., 2016. Large-scale data reporting of paediatric morbidity and mortality in developing countries: it can be done. Arch Dis Child 101: 392.

18. WHO, 2014. Action Plan for Healthy Newborn Infants in the Western Pacific Region (2014-2020). Geneva, Switzerland: Available at: https://www.unicef.org/eapro/regional_action_ plan_new_born_infants.pdf. Accessed May 25, 2017.

19. Obara $\bar{H}$, Sobel $H$, Quality maternal and newborn care to ensure a healthy start for every newborn in the World Health Organization Western Pacific Region. BJOG: Int J Obstetrics Gynaecol 2014;121 (Suppl 4): 154-159.

20. Liu L, Oza S, Hogan D, Perin J, Rudan I, Lawn JE, Cousens S, Mathers C, Black RE, 2015. Global, regional, and national causes of child mortality in 2000-13, with projections to inform post-2015 priorities: an updated systematic analysis. Lancet 385: 430-440.

21. Tosif S, Nasi T, Gray A, Sadr-Azodi N, Ogaoga D, Duke T, 2017. Assessment of the quality of neonatal care in the Solomon Islands. J Paediatr Child Health 54:1 65-171.

22. WHO, UNICEF, 2014. Every Newborn: an Action Plan to End Preventable Newborn Deaths. Geneva, Switzerland: World Health Organization.

23. Enweronu-Laryea C et al., 2015. Basic newborn care and neonatal resuscitation: a multi-country analysis of health system bottlenecks and potential solutions. BMC Pregnancy and Childbirth 15 (Suppl 2): S4.

24. World Health Organization Western Pacific Region, 2016. Coaching for the First Embrace: Facilitators Guide (Early Essential Newborn Care). Geneva, Switzerland: WHO Press.

25. Sobel HL, Silvestre MA, Mantaring JB 3rd., Oliveros YE, Nyunt-U $\mathrm{S}$, 2011. Immediate newborn care practices delay thermoregulation and breastfeeding initiation. Acta Paediatr 100: 1127-1133.

26. Austin A, Langer A, Salam RA, Lassi ZS, Das JK, Bhutta ZA, 2014. Approaches to improve the quality of maternal and newborn health care: an overview of the evidence. Reprod Health 11 (Suppl 2): S1.

27. Donabedian A, 1966. Evaluating the quality of medical care. Milbank Q 44: 166-203.

28. Tong A, Sainsbury P, Craig J, 2007. Consolidated criteria for reporting qualitative research (COREQ): a 32-item checklist for interviews and focus groups. Int $J$ Qual Health Care 19: 349-357.

29. World Bank Group, 2017. Solomon Islands 2016. Available at: https://data.worldbank.org/country/solomon-islands. Accessed September 27, 2018.

30. Auto J, Nasi T, Ogaoga D, Kelly J, Duke T, 2006. Hospital services for children in the Solomon Islands: rebuilding after the civil conflict. J Paediatr Child Health 42: 680-687.

31. Solomon Islands National Statistical Office, 2009. Solomon Islands Population and Housing Census. Honiara, Solomon Islands: Ministry of Finance and Treasury.
32. WHO Regional Office for Europe, Making Pregnancy Safer Assessment Tool for the Quality of Hospital Care for Mothers and Newborn Babies. Available at: http://www.euro.who.int/ data/assets/pdf_file/0008/98792/E93128.pdf. Accessed May 2017.

33. Sa'avu M, Duke T, Matai S, 2014. Improving paediatric and neonatal care in rural district hospitals in the highlands of Papua New Guinea: a quality improvement approach. Paediatr Int Child Health 34: 75-83.

34. World Health Organization, 2016. Interagency List of Medical Devices for Essential Interventions for Reproductive, Maternal, Newborn and Child Health. Geneva, Switzerland: WHO Press.

35. Campbell H, 2005. Pocketbook of Hospital Care for Children. Geneva, Switzerland: WHO.

36. Patton MQ, 1980. Qualitative Evaluation Methods. Thousand Oaks, CA: Sage Publications.

37. Cane J, O'Connor D, Michie S, 2012. Validation of the theoretical domains framework for use in behaviour change and implementation research. Implement Sci 7: 37.

38. Pinnock $\mathrm{H}$ et al., 2017. Standards for reporting implementation studies (StaRI) statement. BMJ 356: i6795.

39. Glaser BG, Strauss AL, 1999. Discovery of Grounded Theory. New York, NY: Routledge.

40. Opiyo N, Were F, Govedi F, Fegan G, Wasunna A, English M, 2008. Effect of newborn resuscitation training on health worker practices in Pumwani Hospital, Kenya. PLoS One 3: e1599.

41. Carlo WA, Wright LL, Chomba E, McClure EM, Carlo ME, Bann $\mathrm{CM}$, Collins M, Harris H, 2009. Educational impact of the neonatal resuscitation program in low-risk delivery centers in a developing country. J Pediatr 154: 504-508.e5.

42. Bookman L, Engmann C, Srofenyoh E, Enweronu-Laryea C, Owen M, Randolph G, Price W, Barker P, Educational impact of a hospital-based neonatal resuscitation program in Ghana. Resuscitation 2010;81: 1180-1182.

43. Musafili A, Essen $B$, Baribwira $C$, Rukundo A, Persson LA, 2013. Evaluating helping babies breathe: training for healthcare workers at hospitals in Rwanda. Acta Paediatr 102: e34-e38.

44. Peacock PJ, Woodman A, McCay W, Bates SE, 2016. Resuscitation of the newborn: simulating for confidence. Cureus 8: e790.

45. Kassab M, Alnuaimi K, Mohammad K, Creedy D, Hamadneh S, 2016. Midwives' experiences, education, and support needs regarding basic newborn resuscitation in Jordan. Clin Nurs Res 25: 291-309.

46. Moshiro R, Ersdal HL, Mdoe P, Kidanto HL, Mbekenga C, 2018. Factors affecting effective ventilation during newborn resuscitation: a qualitative study among midwives in rural Tanzania. Glob Health Action 11: 1423862.

47. Morgan MC, Dyer J, Abril A, Christmas A, Mahapatra T, Das A, Walker DM, 2018. Barriers and facilitators to the provision of optimal obstetric and neonatal emergency care and to the implementation of simulation-enhanced mentorship in primary care facilities in Bihar, India: a qualitative study. BMC Pregnancy Childbirth 18: 420.

48. Das JK, Kumar R, Salam RA, Lassi ZS, Bhutta ZA, 2014. Evidence from facility level inputs to improve quality of care for maternal and newborn health: interventions and findings. Reprod Health 11 (Suppl 2): S4.

49. Bream KDW, Gennaro S, Kafulafula U, Mbweza E, Hehir D, 2005. Barriers to and facilitators for newborn resuscitation in Malawi, Africa. J Midwifery Womens Health 50: 329-334.

50. Mbalinda S, Hjelmstedt A, Nissen E, Odongkara BM, Waiswa P, Svensson K, 2018. Experience of perceived barriers and enablers of safe uninterrupted skin-to-skin contact during the first hour after birth in Uganda. Midwifery 67: 95-102.

51. Nzinga J, Ntoburi S, Wagai J, Mbindyo P, Mbaabu L, Migiro S, Wamae A, Irimu G, English M, 2009. Implementation experience during an eighteen month intervention to improve paediatric and newborn care in Kenyan district hospitals. Implement Sci 4: 45.

52. Anh NN, Tram TT, 1995. Integration of primary health care concepts in a children's hospital with limited resources. Lancet 346: 421-424. 
53. Blacklock C, Goncalves Bradley DC, Mickan S, Willcox M, Roberts N, Bergström A, Mant D, 2016. Impact of contextual factors on the effect of interventions to improve health worker performance in sub-saharan africa: review of randomised clinical trials. PLoS One 11: e0145206.

54. Graham WJ, Bell JS, Bullough $\mathrm{CH}, 2001$. Can skilled attendance at delivery reduce maternal mortality in developing countries? Safe Motherhood Strategies: a Review of the Evidence.
55. Negin J, Martiniuk AL, Farrell P, Dalipanda T, 2012. Frequency, cost and impact of inter-island referrals in the Solomon Islands. Rural Remote Health 12: 2096.

56. Suzana M, Walls H, Smith R, Hanefeld J, 2018. Achieving universal health coverage in small island states: could importing health services provide a solution? BMJ Glob Health 3: e000612.

57. Effective Practice and Organization of Care (EPOC), 2015. EPOC Taxonomy. Available at: https://epoccochraneorg/ epoc-taxonomy. Accessed June 22, 2017. 